\title{
A Stochastic Simulation Model to Assess the Impacts of Electric Vehicle Charging on Power Generation: A Case Study for Qatar
}

\author{
Islam Safak Bayram \\ Qatar Environment and Energy Research Institute, Hamad Bin Khalifa University, Doha, Qatar \\ ibayram@hbku.edu.qa
}

\begin{abstract}
Plug-in electric vehicles (PEVs) have gained popularity in the Gulf Cooperation Council countries as they improve local air quality and are seen as a tool to diversify carbonbased economies. However, power grids in the region are lowinertia systems and often strained by heavy air-conditioning load. In this paper, we present a stochastic simulation study to assess the impacts of PEV charging on the power generation under various penetration and charging schedule scenarios in the State of Qatar. Penetration ratios are obtained from new PEV sales statistics from four different countries, namely Norway, Netherlands, France, and China. Moreover, controlled and uncontrolled scenarios are created to investigate different cases. Actual 5-min electricity load profiles are used and peakconsumption day is chosen to evaluate the worst-case scenario. The results show that current power generation in Qatar has enough spare capacity to fuel up vehicles, however, uncontrolled PEV charging may require additional peak-power generators if the government goal of $10 \%$ PEVs penetration rate is reached. Finally, recommendations for solar-PEV charging is provided by analyzing the actual load and global horizontal irradiance measurements.
\end{abstract}

\section{INTRODUCTION}

Over the last decade, there has been a renewed push towards the adoption of plug-in electric vehicles (PEV) to reduce the carbon footprint of the transportation sector and lower foreign oil dependency [?], [1]. PEV sales, further boosted by monetary incentives and green policies, have reached new records: in Norway, more than half of the new car registration were PEVs in summer 2018, in the United States, cumulative PEV sales have reached one million and global sales have surpassed four million [2]. As the cost of lithium-ion batteries falls, from $\$ 1000 \mathrm{kWh}$ in 2010 to $\$ 130-\$ 150 \mathrm{kWh}$ in 2017 , PEVs are expected to become the main mode of passenger transportation.

According to World Trade Organization [3], crude oil, lightduty vehicles, and car parts constitute one of the highest volumes of international trade. To that end, oil-rich countries, such as the ones in the Gulf region who dominate such trading markets, are developing roll-out strategies for electric transportation. The State of Qatar, a country with abundant hydrocarbon resources -ninth highest oil reserves and third highest proved natural gas reserves-, has recently decided to manufacture PEVs with a Japanese partner and promote electric transportation in the country. In Qatar, PEV adoption target has been set at $10 \%$ of all cars by 2030 [4] and the local utility company has already started to deploy public charging stations.

In the GCC region, there are a number of efforts towards electrification of transportation. In the United Arab Emirates, government officials have started to replace public vehicles, e.g., buses, airport vehicles, and promote PEVs in ride-hailing applications [5]. Similarly, long-distance electrified trips have been carried out to boost PEV sales [6]. On the other hand, a number of region-specific challenges exist beyond grid-related ones. Batteries used in current PEV models are not designed to operate under harsh climates. High ambient temperatures and dust combined with fast-charging of vehicles significantly degrade battery lifetime and threaten the economic viability of vehicles. Also, there is a need to design chargers that can operate above 50-celsius ambient temperature which is very typical during summer afternoons in many GCC countries [7].

As previous research shows, reaching high PEV penetration goals necessitates the power grid to be able to energize significant amounts of vehicles [1]. On the one hand, power grid should have enough generation capacity (both energy and power), and the charging schedule of PEVs should not violate grid operating limits. Moreover, Qatar is ranked as the highest in energy consumption per capita, the peak electricity consumption has been growing by $5-6 \%$ during the last decade, and subsidized electricity tariffs lead to overconsumption [8]. To that end, in order to realize such penetration levels, the impacts of PEV charging on the grid should be carefully investigated. In this paper, we present a Monte Carlo-based simulation study to assess the impacts of PEV charging on the power generation under various penetration and charging schedule scenarios. The results show that current power generation in Qatar can generate enough energy to fuel up vehicles, however, uncontrolled PEV charging may require additional peak-power generators.

\section{LitERATURE REVIEW}

A large and growing body of literature has investigated the impacts of PEV charging on the grid [1], [9]-[13]. Reference [1] assessed the impacts of controlled and uncontrolled PEV charging on the grid components. Simulation-based case studies were carried out in [9] to show that impacts of PEV 


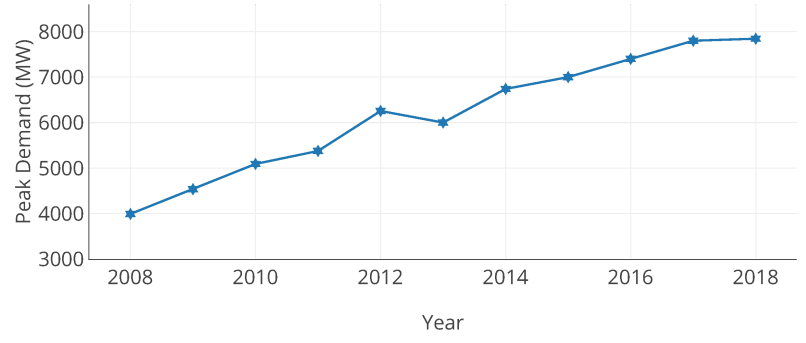

(a) Peak electricity consumption.

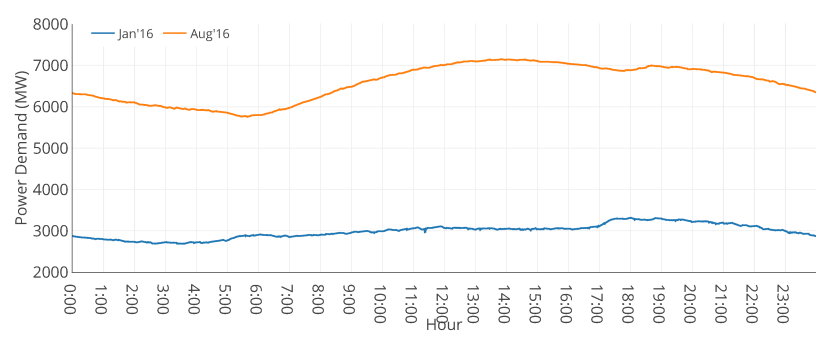

(b) Average profiles in January and August.

Fig. 1: Electricity consumption statistics in Qatar.

demand on the distribution network and more specifically on power quality. Simulation scenarios considered slow charging methods with typical residential load profiles in Belgium. A number of studies, including [10]-[13] have examined the energy and power requirements of PEVs in different parts of the world. Ref. [10] developed a stochastic model to capture the energy needs of PEVs, both in time (e.g., charge start time) and quantity (e.g., battery state-of-charge), in the United States using national household travel surveys. Such surveys were also used in [13] to assess the additional load introduced by PEV chargings on an hourly basis. Moreover, a similar study is presented in [11] to investigate the impacts of PEV charging in Australian electricity markets. One of the earliest studies on the impacts of PEV charging is presented in [12] and authors assumed the scenario in which half of the vehicles were plugged-in at $5 \mathrm{pm}$ and the other half started charging at $6 \mathrm{pm}$ using $1.4 \mathrm{~kW}$ and $6.6 \mathrm{~kW}$ chargers. It is important to note that even though there can be similarities with methods, PEVgrid impact studies must be carried out with data-sets obtained from local case study. To the best of author's knowledge, this is the first study investigating the impacts of PEV charging in Qatar and the GCC region.

\section{PEV CHARGING IMPACTS}

\section{A. Electricity Consumption in Qatar}

This paper seeks to address the following question: Can the power grid in Qatar fuel significant amounts of PEVs such as $10 \%$ of vehicles with the current generation capabilities? To answer this question, we highlight and present some of the most important electricity consumption patterns [8]. In Qatar, due to: (1) subsidized electricity prices; (2) abundant naturalgas resources; and (3) high necessity for air conditioning and water cooling, the load factor of daily electricity consumption is high compared to other countries meaning that the difference between the minimum and the maximum load is low. On the other hand, due to seasonal weather variations, there are significant differences between the summer and winter months. The current installed capacity in Qatar is $8.5 \mathrm{GW}$, while peak demand in 2018 reached 7834 MW on Jul 12, 2018. Overview of peak demand and monthly average daily load profiles are presented in Fig. 1. As shown in Fig.1(a), peak consumption has been doubled over the last decade, hence it is critical to coordinate PEV demand in order not to coincide with peak demand. Furthermore, as revealed in Fig. 1(b), there is a significant amount of unused capacity in winter months, while the summer load is close to the generation limits. Therefore, this study focuses on summer months as they are more critical.

Electricity sector in Qatar, and in the GCC region at large, energizes air conditioning which is a must to maintain comfortable life style for almost ten months of the year. Moreover, due to lack of natural water resources and aquifers, seawater is desalinated through energy-hungry water treatment plants powered by electricity. To that end, it is very critical for grid operators to keep the grid operational with minimum system interruptions [14], [15].

\section{B. Simulation Set-up}

A stochastic simulation model is developed to assess the impacts of PEV charging on power generation. For PEV sale statistics, five scenarios are considered. The first four scenarios assume that new PEV registrations in the next five years will mimic PEV sales in Norway, Netherlands, France, and China. The last scenario is a what-if scenario in which ten percent of vehicles are assumed to be PEVs as targeted by the government. The scenarios are chosen to represent aggressive, mild, and slow PEV penetration ratios (see Table I). Annual new car registration figures for Qatar are presented in Ministry of Statistics and Planning reports [16] and due to the availability of data, last two years average is taken as 46 thousand new registration each year.

According to official census statistics [17], $48 \%$ of the residents live in villa type buildings, while the rest resides in apartments. Therefore, it is assumed that people in villas will drive SUVs and have access to a dedicated charger, while the rest of the population drive sedans and use public charging stations. Battery packs are chosen from current popular models: for SUV models battery sizes are $B_{\mathrm{SUV}} \in$ $\{80,75,90,95,70\} \mathrm{kWh}$ while sedan battery packs are $B_{\text {Se }} \in\{21,24,23,16.4,16,24,50\}$ kWh [1]. Battery charging powers follow the UK standards (from level 2 charger to fast DC charger), for SUVs it is assumed as $C_{\mathrm{SUV}} \in$ $\{7.2,22,50\} \mathrm{kW}$ and for sedans $C_{\mathrm{Se}} \in\{3.6,7.2,22,50\}$ [1]. It is further important to note that the probability of each charger type, $C_{\mathrm{SUV}}$ and $C_{\mathrm{Se}}$, is equal. Suppose $n$ is the index of SUVs, then the probability of $n$th SUV to use $7.2 \mathrm{~kW}$ 
TABLE I: PEV Sales as Percentage (\%) of New Car Registration / \% of Peak Demand Increase.

\begin{tabular}{lccccc}
\hline & Year 1 & Year 2 & Year 3 & Year 4 & Year 5 \\
\hline Norway & $3.27 / 0.38$ & $6 / 1.14$ & $13.71 / 2.79$ & $23.63 / 5.05$ & $28.76 / 7.47$ \\
Netherlands & $1.02 / 0.11$ & $5.38 / 0.79$ & $3.89 / 1.27$ & $9.74 / 2.24$ & $6.39 / 2.82$ \\
France & $0.34 / 0.03$ & $0.55 / 0.10$ & $0.72 / 0.19$ & $1.22 / 0.31$ & $1.46 / 0.45$ \\
China & $0.06 / 0.004$ & $0.09 / 0.01$ & $0.38 / 0.06$ & $0.99 / 0.16$ & $1.37 / 0.29$ \\
\hline
\end{tabular}

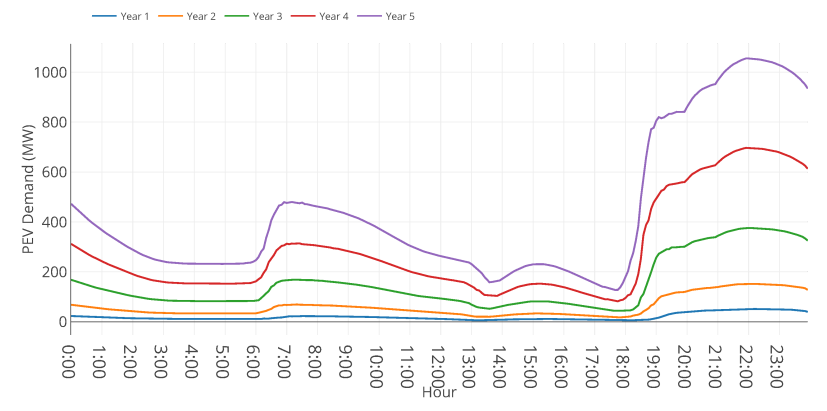

(a) Simulation for highest penetration case.

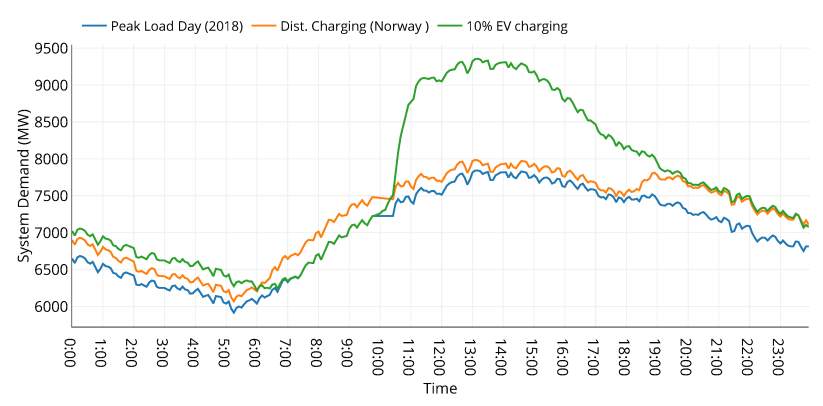

(b) Aggregate system load on peak day (MW).

Fig. 2: Additional demand introduced by PEVs in Qatar.

charger is $\mathbb{P}\left(C_{\mathrm{SUV}}(n)=7.2\right)=\frac{1}{3}$. Similarly, let $m$ be the index of sedans, then $\mathbb{P}\left(C_{\mathrm{Se}}(m)=3.6\right)=\frac{1}{4}$.

A critical part of the PEV chargings is the schedule of PEV charging. As discussed in the literature review, several studies used travel surveys, while a few of them assumed that people start charging right after they go home from work. Since in Qatar no such travel surveys exist, we made the following assumptions. SUVs charging start time follows a normal distribution with a mean starting time of 9:30 pm and a standard deviation of one hour. In the simulation, one day is discretized into five-minute intervals with a total of 288 intervals. Hence, SUV starting times can be written as $S_{\mathrm{SUV}} \sim \mathcal{N}(260,12)$. Similarly, half of the sedans will charge in the morning at 9 am $S_{\mathrm{Se}} \sim \mathcal{N}(108,12)$ and the other half charges after work at $3 \mathrm{pm} S_{\mathrm{Se}} \sim \mathcal{N}(180,12)$.

\section{REsults}

The simulation, developed in MATLAB, was run with the parameters given in the previous section, repeated 100 times with different random number generator seeds, and the averaged results are presented in Fig. 2. Due to space limitations, only the case for Norway,-highest penetration rate-, is presented for a five-year demand. As shown in Fig. 2(a), high demand occurs at night due to the charging of SUVs and reduces in the morning. This case is acceptable for the grid operator as the peak system demand occurs in the afternoon during summer months and plenty of capacity is available in winter months (see Fig. 1(b)).

During the year 2018, the peak consumption day was July 12, 2019. In Fig. 2(b), the worst-case scenario is simulated in which $10 \%$ of the vehicles are assumed to be PEVs (150000 vehicles) and all vehicles start charging at $2 \mathrm{pm}$ $(\sim \mathcal{N}(168,12))$ on the peak day. In this case, the aggregated PEV load exceeds $8.5 \mathrm{GW}$ generation limit and increases the peak demand by $19.2 \%$ which is not desirable by the grid operator. On the other hand, as shown in Table I, the highest peak demand increase is $7.47 \%$ in year 5 of the Norway case. In all other cases, the current power grid is capable of handling the excess demand.

Results presented above show the potential impacts of PEV charging on current grid operations. The state of Qatar has recently announced to tender $500 \mathrm{MW}$ PV solar farm, and 350 MW will be operational by 2020. In this case, grid operator prefers vehicles to be served during the times of high PV generation. In Fig.3, peak electricity generation and global horizontal irradiance measurements taken in Qatar [8] are presented. The figures show that there is a mismatch between the times of PV generation and the peak electricity demand. Hence, charging vehicles from 5 am to 11 am would reduce the peak demand introduced by the PEVs. This way, EV demand can be used to flatten the "duck curve" and reduce ramping requirements of natural gas generators.

Another natural question arises on the amount of energy required to replace gas vehicles in the country. According to Woqod Company which is the main operator of the gas stations in Qatar [18], 4.31 Billion liters of gas was sold for light-duty vehicles in 2017 (excluding diesel which is used for heavy-duty trucks). Using the US EIA's calculation methods, 4.31 Billion liters of oil could be translated as $40.2 \mathrm{TWh}$ of electricity. It is further assumed that PEVs use energy with four times the efficiency of combustion engine vehicle, then $10.05 \mathrm{TWh}$ of electricity would be needed. Roughly, $8 \%$ of electricity is lost during transmission and distribution, then the amount of energy to be generated would be 10.93 TWh. We examine the grid's theoretical serving capacity by calculating excess energy that would be generated with peak capacity of 


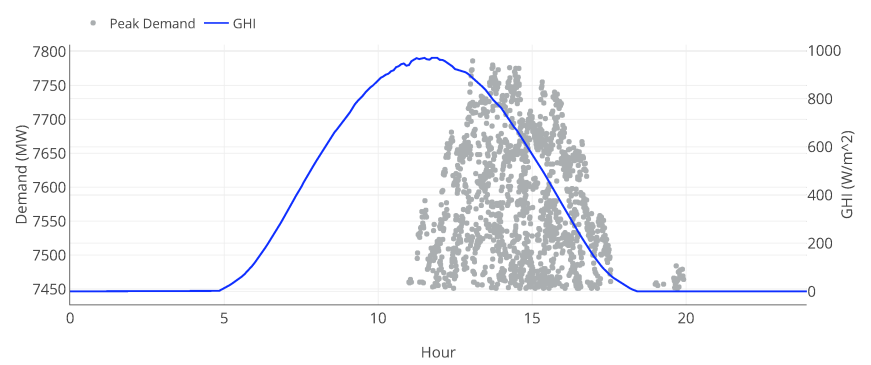

(a) Peak demand and GHI in Jun'18.

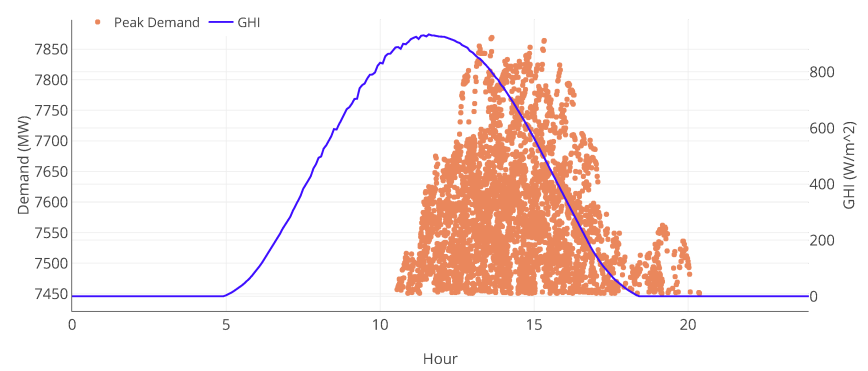

(b) Peak demand and GHI in Jul' 18.

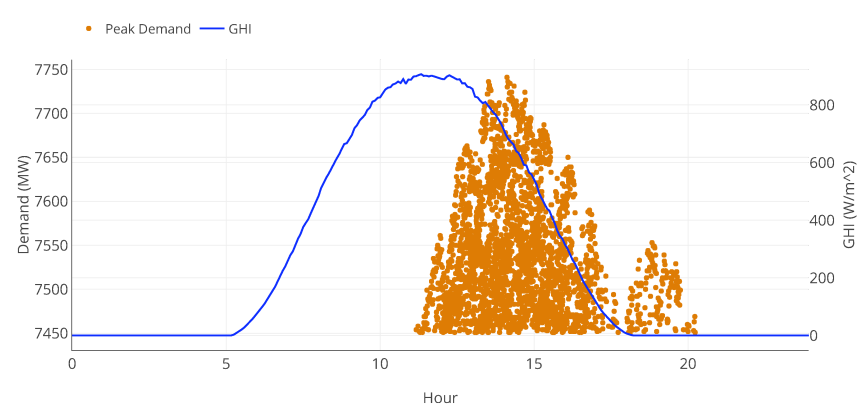

(c) Peak demand and GHI in Aug'18.

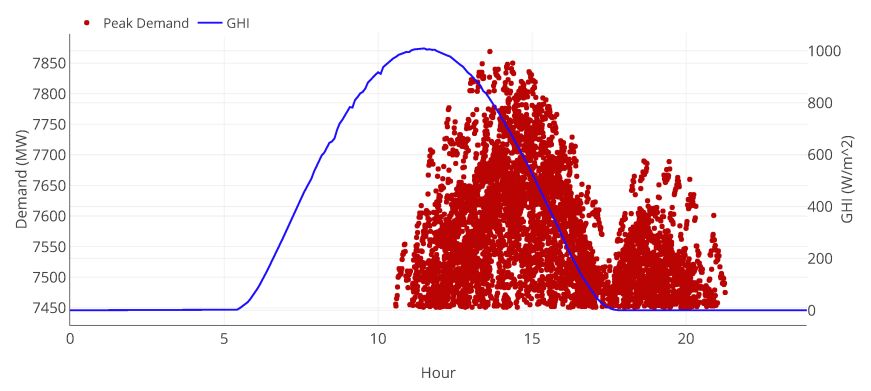

(d) Peak demand and GHI in Sept'18.

Fig. 3: Peak demand in summer 2018 (top 5\%) and average global horizontal irradiance $(\mathrm{GHI})$. Each dot represents oneminute long system demand.
8.5 GW minus the peak day demand. Then, the daily spare capacity would be $0.035 \mathrm{TWh}$ which indicates that even with today's power grid has the potential to handle significant (up to $85 \%$ ) PEV penetration levels.

\section{CONCLUSiOnS AND Future WORK}

Electrification of transportation have emerged as a solution to remedy urban air quality and diversify economies in carbonrich gulf region [19]. A number of technical challenges exists agains the penetration of PEVs. The first one is that high ambient temperatures degrade the lifetime of battery, hence new charging methods needs to be developed. Second, due to zero tax and low oil prices, owning and operation cost of conventional vehicles are lower than PEVs. Third, power grids are often strained by heavy air-conditioning load. Hence, in this paper, a stochastic simulation study has been presented to examine the additional load introduced by PEV integration under various penetration scenarios. Actual load profiles were used to assess the worst-case scenario and results showed that uncontrolled charging would exceed grid generation capacity. It is further shown that current power grid can energize a significant portion of PEVs if smart charging algorithms are developed. In the last part, we presented that in the presence of PV generation, charging PEVs before 11 am would reduce peak consumption. This way, PEVs can be used to flatten the "duck curves" and reduce associated costs.

In the future, we aim to expand current study in a number of ways. First, we need to obtain a dataset representative of vehicle segments (e.g., small-,mid-, large-SUVs/sedans), actual driving and parking statistics, and vehicle sales predictions. These inputs will improve the output of the paper. Moreover, we need to take two important things into account: (1) a sizable portion of the battery will be used for air-conditioning and (2) due to high ambient temperature in summer only some portion of the battery (e.g., $50 \%$ to $80 \%$ state of charge) can be cycled. These two parameters will allow us to determine how frequently and when PEVs need a recharge during the day. However, obtaining such results may require experimental studies or surveys which may take time to occur.

\section{REFERENCES}

[1] I. S. Bayram and A. Tajer, Plug-in Electric Vehicle Grid Integration. Artech House, 2017.

[2] [Online]. Available: https://about.bnef.com/blog/ cumulative-global-ev-sales-hit-4-million/

[3] World trade statistical review 2017. [Online]. Available: https: //www.wto.org/english/res_e/statis_e/wts2017_e/wts17 toc_e.htm

[4] Qatar seeks to increase green cars to $10 \%$ by 2030 . [Online]. Available: QatarNewsAgency

[5] Electric vehicles struggle to take off in dubai [Online]. Available: https://www.arabianbusiness.com/transport/ 410247-electric-vehicles-fail-to-take-off-in-dubai

[6] The electric cars will go on a 520-km trip from abu dhabi to muscat. [Online]. Available: https://www.khaleejtimes.com/nation/abu-dhabi/ twelve-electric-cars-start-2000-km-trip-to-spread-the-green-message

[7] P. Kubiak, Z. Cen, C. M. López, and I. Belharouak, "Calendar aging of a $250 \mathrm{kw} / 500 \mathrm{kwh}$ li-ion battery deployed for the grid storage application," Journal of Power Sources, vol. 372, pp. 16-23, 2017.

[8] I. S. Bayram, F. Saffouri, and M. Koc, "Generation, analysis, and applications of high resolution electricity load profiles in qatar," Journal of Cleaner Production, pp. -, 2018. 
[9] K. Clement-Nyns, E. Haesen, and J. Driesen, “The impact of charging plug-in hybrid electric vehicles on a residential distribution grid," IEEE Transactions on power systems, vol. 25, no. 1, pp. 371-380, 2010.

[10] N. H. Tehrani and P. Wang, "Probabilistic estimation of plug-in electric vehicles charging load profile," Electric Power Systems Research, vol. 124, pp. 133-143, 2015

[11] G. Mills and I. MacGill, "Potential power system and fuel consumption impacts of plug in hybrid vehicle charging using australian national electricity market load profiles and transportation survey data," Electric Power Systems Research, vol. 116, pp. 1-11, 2014.

[12] S. W. Hadley and A. A. Tsvetkova, "Potential impacts of plug-in hybrid electric vehicles on regional power generation," The Electricity Journal, vol. 22, no. 10, pp. 56-68, 2009

[13] C. Weiller, "Plug-in hybrid electric vehicle impacts on hourly electricity demand in the united states," Energy Policy, vol. 39, no. 6, pp. 37663778, 2011.

[14] T. N. Atalla and L. C. Hunt, "Modelling residential electricity demand in the gcc countries," Energy Economics, vol. 59, pp. 149-158, 2016.

[15] İ. Ş. Bayram and H. Mohsenian-Rad, "An overview of smart grids in the gcc region," in Smart City 360. Springer, 2016, pp. 301-313.

[16] Qatar ministry of statistics and planning. [Online]. Available: https://www.mdps.gov.qa/en/statistics1/Pages/default.aspx

[17] I. S. Bayram and M. Koc, "Demand side management for peak reduction and pv integration in qatar," in 2017 IEEE 14th International Conference on Networking, Sensing and Control (ICNSC), May 2017, pp. 251-256.

[18] Woqod annual report 2017. [Online]. Available: http://www.woqod. com/EN/AboutUs/InvestorRelations/Pages/FinancialReporting.aspx

[19] H. Omidvarborna, M. Baawain, and A. Al-Mamun, "Ambient air quality and exposure assessment study of the gulf cooperation council countries: A critical review," Science of the Total Environment, vol. 636, pp. 437448, 2018. 